\title{
DESCENDO OU RISING? PADRÕES ENTOACIONAIS DE PERGUNTAS TOTAIS DA LÍNGUA INGLESA E DA LÍNGUA PORTUGUESA POR FALANTES BRASILEIROS
}

\section{Descendo or Rising? Intonational Patterns in American English and Brazilian Portuguese Polar Questions by Brazilian Speakers}

\author{
Leonice PASSARELLA dos REIS, EAM ${ }^{1}$
}

\begin{abstract}
RESUMO: Os benefícios do ensino de pronúncia no processo de aquisição de uma língua adicional (LA) são inquestionáveis. No entanto, determinar a quantidade adequada e os aspectos da pronúncia mais relevantes para dar meios ao falante de uma LA para que se comunique de modo inteligível é não só uma necessidade, mas também um desafio. Com o intuito de colaborar com pesquisas na área de ensino de pronúncia, este estudo investigou os padrões entoacionais de interrogativas totais neutras realizadas por cinco falantes do PB em inglês e em PB, e realizadas por um falante do inglês americano em inglês. A análise foi realizada com o uso do Praat, seguindo a notação do Sistema Métrico Autossegmental. Os resultados indicaram que os padrões entoacionais produzidos pelos falantes brasileiros incluíram padrões transferidos diretamente do PB (/LH*L\%/), padrões do inglês (/L*H\%/) e outros padrões sugestivos de uma língua em desenvolvimento. Além da transferência linguística, o tempo de aprendizagem e a idade de início da aprendizagem parecem ter exercido alguma influência em tais produções.
\end{abstract}

PALAVRAS-CHAVE: Interrogativas Totais Neutras; Língua Adicional; Transferência Linguística da L1.

ABSTRACT: The benefits of the teaching of pronunciation on the learning process of additional languages (AL) are undeniable. However, determining the amount and the pronunciation aspects that are relevant to enable intelligible speech is not only a need, but also a challenge. With the purposes of contributing to research in the area, this study sets out to investigate the intonational patterns of neutral polar questions produced by BP speakers in English and in BP, and by an American English speaker in English. The analysis was carried out with the use of Praat and the notation of the Autosegmental Metric System. Results showed that the intonational patterns produced by the BP speakers were (1) patterns directly transferred from their L1 (/LH*L\%/), (2) English patterns $(/ \mathrm{L} * \mathrm{H} \% /)$, and (3) other intonational patterns that suggest the existence of an LA still in development. Besides L1 transfer, time of experience with learning and the age of onset of learning may have influenced the production of the intonational patterns investigated.

KEYWORDS: Neutral Polar Questions; Additional Language; L1 Transfer.

\footnotetext{
${ }^{1}$ Doutoranda no Programa de Estudos Linguísticos e Literários em Inglês da Universidade Federal de Santa Catarina. Docente de Língua Inglesa na Escola de Aprendizes-Marinheiros de Santa Catarina (EAM), onde é também coordenadora da disciplina.
} 


\section{INTRODUÇÃO}

O ensino de pronúncia pode trazer benefícios inquestionáveis à aquisição de uma língua adicional (LA). Entretanto, é necessário definir a quantidade adequada e os aspectos mais importantes a serem ensinados (BERNS, 2008; JENKINS, 2003). De acordo com Berns (2008), esses aspectos da pronúncia devem ser considerados dentro de uma comunidade específica de falantes. No Brasil, algumas pesquisas foram conduzidas principalmente no nível segmental (por exemplo, CRUZ, 2003, 2008, 2010; SCHADECH; SILVEIRA, 2013), mas muita pesquisa ainda é necessária para determinar que aspectos de pronúncia (no nível segmental ou suprassegmental) podem comprometer a comunicação de falantes do português brasileiro (PB) em inglês.

Com o intuito de colaborar com pesquisas na área, este estudo tem como objetivo investigar os padrões entoacionais de interrogativas totais neutras realizadas por falantes do PB em inglês e em português, uma vez que tais padrões diferem nas duas línguas. Os dados investigados são oriundos da variedade carioca (Rio de Janeiro), para o português, e do inglês americano (da Califórnia), para o inglês controle. As amostras foram analisadas seguindo a notação do sistema métrico autossegmental (L e H) e os resultados explicados à luz da transferência linguística e da interlíngua. A seguir, os principais conceitos teóricos para este estudo são brevemente revisados.

\section{REFERENCIAL TEÓRICO}

\subsection{Prosódia e Entoação}

Este trabalho está inserido no campo da prosódia, mais especificamente, da entoação. Prosódia refere-se aos aspectos "fônicos relativos aos fonemas da língua dentro de uma sílaba ou vocábulo" (SEARA, 2008, p. 22), cujos parâmetros acústicos são (1) intensidade, (2) curva de F0 e (3) duração. Entoação refere-se aos aspectos relativos "a unidades maiores" como as interrogativas, que têm como parâmetro acústico a curva de F0, ou seja, o contorno do pitch, objeto de estudo deste trabalho. 


\subsection{Sistema Métrico Autossegmental}

O Sistema Métrico Autossegmental, iniciado por Pierrehumbert em 1980, tem uma abordagem fonológica e considera a entoação como uma sequência de tons que se distinguem pela sua altura - baixo $(\mathrm{L})$ ou alto $(\mathrm{H})$. A notação utilizada representa o contorno como sendo uma sequência contendo acentos do pitch e de tons limítrofes “edge tones" (LADD, 1996; 2008).

$\mathrm{O}$ acento do pitch pode ser composto por um $\mathrm{L}$ ou por um $\mathrm{H}$ ou, ainda, pela combinação dos dois tons (LH, HL). Quando o tom ( $\mathrm{L}$ ou H) estiver acompanhado de um asterisco (*), significa que ele é o tom nuclear do acento do pitch ( $\mathrm{L}^{*}$ ou $\left.\mathrm{H}^{*}\right)$. Quando o L ou o $\mathrm{H}$ contiver o diacrítico ${ }^{-}$, representa um tom que antecede ou precede o nuclear $\left(\mathrm{L}^{*}\right.$ ou $\left.\mathrm{H}^{*}\right)$. Quando o acento do pitch for bitonal, o + pode ser usado para unir os dois tons $\left(\mathrm{L}^{*}+\mathrm{H}^{-} \text {, por exemplo }\right)^{2}$.

Os tons limítrofes "edge tones" são os eventos tonais nos limites do domínio prosódico (LADD, 1996) e são divididos em dois tipos: tons de fronteira e acento frasal. Os tons de fronteira são constituídos por apenas um tom, ou seja, apenas um L ou um H, e estão relacionados com o final do sintagma entoacional. O diacrítico que os representa é o \%. O L\% indica a ausência de uma subida final. Se for antecedido por um L, o L\% indica uma queda até o limite mínimo do range do falante. Se for antecedido por um $\mathrm{H}$, o L\% indica que o $\mathrm{H}$ foi sustentado na mesma altura (LADD, 1996). No entanto, neste estudo, quando houve a sustentação de um tom que antecede o de fronteira, seja ele um $\mathrm{L}$ ou um $\mathrm{H}$, a mesma notação deste tom anterior ao de fronteira foi utilizado ( $\mathrm{L}^{*} \mathrm{~L} \%$, $\left.\mathrm{H}^{*} \mathrm{H} \%\right)$. O H\% indica que há uma subida ao final do sintagma entoacional. $\mathrm{O}$ acento frasal (ou tom frasal) ocorre entre o último acento do pitch e o tom de fronteira, ou seja, é o tom que geralmente antecede o tom de fronteira. Ele é o pico (ou o vale) ao fim da palavra nuclear.

Outro diacrítico importante para este trabalho é o !, que representa o fenômeno conhecido como downstep (LADD, 1996). Ele indica que a produção ainda não atingiu a altura desejada para ser considerada um $\mathrm{H}$ em si. Neste estudo, ele é usado exclusivamente nos tons de fronteira (!H\%), que foram essenciais para a distinção entre

\footnotetext{
${ }^{2}$ Os símbolos + e - usados para (1) unir dois tons de um acento de pitch bitonal e (2) indicar um tom anterior ou posterior, respectivamente, podem ser omitidos sem comprometer a descrição do contorno melódico (LADD, 1996) e, portanto, não foram considerados neste trabalho.
} 
os padrões entoacionais das interrogativas totais em inglês produzidas (1) por alguns dos informantes brasileiros e (2) pelo informante americano.

\subsection{Padrões Entoacionais do PB e do Inglês}

De acordo com Moraes (2008), o contorno melódico do núcleo das interrogativas totais do PB pode apresentar três notações distintas: (1) LH*L\%, (2) $\mathrm{L}+>\mathrm{H}^{*} \mathrm{~L} \%{ }^{3}$ e $(3) \mathrm{H}+[\mathrm{LH}]^{*} \mathrm{~L} \%$. A notação $\mathrm{LH}^{*} \mathrm{~L} \%$ representa o contorno melódico das interrogativas totais neutras. Neste estudo, o termo "neutra" indica que a pergunta é feita buscando uma informação desconhecida, ou seja, a resposta à pergunta é um dado completamente novo ao locutor. Por um lado, as notações (2) e (3) se distinguem dessa por terem ou o $\mathrm{H}$ com alinhamento antecipado (2) ou por terem o pré-núcleo alto $(\mathrm{H})$ seguido de uma queda com elevação no núcleo (LH) (3), indicando que a pergunta deixou de ser neutra e passou a ser retórica (2) e de descrença/dúvida (3), respectivamente. Por outro lado, as três notações se assemelham por apresentarem o mesmo tom de fronteira L\%. Apenas as interrogativas totais produzidas como neutras no PB, ou seja, produzidas como se o locutor não soubesse a resposta, foram analisadas comparativamente com as produzidas no inglês.

Hedberg, Sosa e Fadden (2004) destacam quatro possíveis padrões para as interrogativas totais (positivas) no inglês americano: (1) $\mathrm{H}^{*} \mathrm{HH} \%$, (2) $\mathrm{H}^{*} \mathrm{LL} \%$, (3) $\mathrm{H}^{*} \mathrm{HL} \%$ e (4) L*HH\%, sendo essa última notação a que representa o contorno melódico das interrogativas totais neutras. Os outros contornos (1, 2 e 3 ) diferem do (4) não só no tom de fronteira, mas também no tom frasal e na tônica. $\mathrm{O}$ contorno representado pela notação $\mathrm{H}^{*} \mathrm{HH} \%$ (1) indica que a interrogativa deixou de ser neutra e passa a denotar surpresa, ou seja, deixa de ser uma pergunta real. No caso dos contornos (2) e (3), há uma indicação de que uma resposta positiva é esperada. Neste trabalho, a notação utilizada excluiu a notação do acento frasal (ou tom frasal) quando esse tom fosse o mesmo que o de fronteira. Por exemplo, a notação para a interrogativa total neutra utilizada foi $\mathrm{L}^{*} \mathrm{H} \%$ em vez de $\mathrm{L}^{*} \mathrm{HH} \%$. Essa escolha se deu pelo fato de a notação do tom que antecede o de fronteira, quando igual, não acrescentar informação relevante para a análise a que esse trabalho se propõe realizar.

As amostras dos participantes com o nível básico e intermediário de proficiência em inglês foram analisadas de modo a verificar se esses padrões para as interrogativas

\footnotetext{
${ }^{3} \mathrm{O}$ símbolo > indica o alinhamento antecipado do tom (MORAES, 2008).
} 
totais neutras do PB e do inglês $\mathrm{LH}^{*} \mathrm{~L} \%$ e $\mathrm{L} * \mathrm{H} \%$, respectivamente, foram seguidos ou não, discutindo os resultados encontrados à luz da transferência linguística e do conceito de interlíngua.

\subsection{Proficiência, Transferência Linguística e Interlíngua}

Com o intuito de buscar atenuar o aparecimento de outras variáveis que pudessem comprometer a coleta de dados e a qualidade das interrogativas gravadas, $o$ nível de proficiência dos participantes cujas amostras foram analisadas foi controlado. Tendo em vista este estudo ter material de produção oral como corpus de análise, proficiência, aqui, refere-se à habilidade linguística demonstrada pelos informantes ao descrever imagens oralmente em inglês e foi definida através do julgamento dessas descrições por três avaliadores altamente proficientes em inglês (SILVEIRA, 2011).

Transferência Linguística se refere à influência da língua materna durante (1) o processo de aquisição de uma língua adicional (LA) e (2) o desenvolvimento da Interlíngua. Também conhecida como a Língua do Aprendente "Learner's Language" (ECKMAN, 2004), o termo interlíngua, aqui, refere-se à LA em desenvolvimento. Se for considerado que a LA estudada está sempre em desenvolvimento conforme a sua utilização ou não, mesmo após a interrupção de sua instrução formal, o "aprendente A" terá sempre a sua própria interlíngua, que difere à do "aprendente B", de acordo com fatores como (1) a frequência de utilização da língua, (2) o tempo de ausência de contato com a língua e (3) o contexto de utilização (FIVE GRACES GROUP, 2009). Ao buscar investigar as amostras de informantes com diferentes níveis de proficiência, buscou-se investigar o desenvolvimento da interlíngua em termos entoacionais, buscando explicações na transferência linguística.

De acordo com Eckman (2004), a influência da língua materna na pronúncia da LA sempre foi investigada e sustentada. No entanto, essa influência é capaz de explicar apenas alguns desvios do que se deseja alcançar na produção realizada na LA (ECKMAN, 2004). O presente estudo buscou investigar se o padrão entoacional de interrogativas totais neutras produzidas pelos falantes brasileiros em português apresenta algum desvio de produção em relação ao da LA quando produzidas na LA e se esse é um desvio que pode ser explicado por essa influência conhecida como transferência linguística. 


\subsection{Perguntas de Pesquisa e Hipóteses}

Esta pesquisa buscou entender se a diferença no padrão das interrogativas totais neutras $\left(\mathrm{LH}^{*} \mathrm{~L} \%\right.$ versus $\left.\mathrm{L}^{*} \mathrm{H} \%\right)$ afeta a maneira como os falantes brasileiros produzem os padrões das interrogativas totais neutras em inglês. Para isso, respondeu às seguintes perguntas de pesquisa:

- Pergunta 1: Quais são os padrões entoacionais das interrogativas totais encontradas nas produções dos informantes brasileiros em PB?

Hipótese 1: O padrão encontrado será o da interrogativa total neutra $\mathrm{LH}^{*} \mathrm{~L} \%$ em sua maioria, já que as perguntas foram realizadas sem a visualização da resposta.

- Pergunta 2: Quais são os padrões entoacionais das interrogativas totais encontradas nas produções do informante americano em inglês?

Hipótese 2: O padrão encontrado será o da interrogativa total neutra $\mathrm{L} * \mathrm{H} \%$ em sua maioria, já que as perguntas foram realizadas sem a visualização da resposta.

- Pergunta 3: Quais são os padrões entoacionais das interrogativas totais encontradas nas produções dos informantes brasileiros em inglês?

Hipótese 3: O padrão encontrado será o da interrogativa total neutra do português LH*L\% em sua maioria.

- Pergunta 4: Há diferença na produção dos padrões entoacionais das interrogativas totais neutras em inglês dos participantes com nível básico de proficiência e dos participantes com nível intermediário de proficiência?

Hipótese 4: Haverá diferença na produção entre os dois grupos de participantes.

- Pergunta 5: Os resultados podem ser explicados à luz da transferência linguística?

Hipótese 5: Sim. Por sofrerem menos influência da L1, os participantes mais proficientes terão menos interferência dos padrões entoacionais do PB do que os menos proficientes. 


\section{MÉTODO}

Esse trabalho contou com 13 participantes: um falante de inglês (americano), nove brasileiros falantes de inglês e três avaliadoras para o teste do nível de proficiência.

$\mathrm{Na}$ época da coleta de dados, o informante americano, monolíngue, do sexo masculino, natural da Califórnia, nos Estados Unidos, onde viveu a maior parte de sua vida, tinha 41 anos de idade, residia no Canadá e interagia com falantes de inglês como LA pelo período de duas a quatro horas diariamente. Esse informante se voluntariou a fazer parte da pesquisa e teve os dados coletados através da cooperação de uma pesquisadora brasileira que também residia no Canadá na época em que a pesquisa foi realizada. Ele assinou um Termo de Consentimento, preencheu um questionário no qual forneceu dados pessoais e de interação com falantes de outras línguas ${ }^{4}$, gravou, com a interlocução de sua esposa, as duas versões do diálogo entre John e Mary em inglês, criadas para esta pesquisa.

Os nove participantes brasileiros, naturais ou da cidade do Rio de Janeiro ou da Grande Rio (cidades circunvizinhas), onde viveram a maior parte de sua vida, tinham idade média de 23,67 anos (mínima de 18 e máxima de 39 anos) na época da coleta de dados e eram todos militares da Marinha do Brasil. Quando os dados foram coletados, sete dos nove participantes eram Aprendizes-Marinheiros, em seu início de carreira, nunca haviam estado em um país cuja L1 fosse inglês, não falavam outra língua adicional senão a inglesa e recebiam instrução formal de língua inglesa, com exposição mínima de 135 minutos e máxima de 300 minutos por semana. Os outros dois participantes brasileiros se distinguem dos demais por já serem comandantes na época da coleta de dados, por já haverem estado em países cuja L1 fosse o inglês e por não receberem instrução formal de inglês na época da coleta de dados.

Durante a coleta de dados, os nove informantes brasileiros foram encontrados individualmente três vezes. No primeiro encontro, eles assinaram um Termo de Consentimento, responderam a um questionário ${ }^{5}$ que investigou, além de dados pessoais, a experiência com a aprendizagem e com o uso da língua inglesa, fizeram uma atividade de produção oral, adaptada a partir de Silveira (2011), que consistia na

\footnotetext{
${ }^{4}$ Esse questionário foi criado por Silveira (2011).

${ }^{5}$ Questionário adaptado de Silveira (2011).
} 
descrição de uma série de figuras para a elaboração do teste de proficiência, e receberam a versão em inglês do diálogo a ser gravado, criado para esta pesquisa. No segundo encontro, fizeram a gravação do diálogo entre John e Mary, em inglês, com a interlocução da pesquisadora. No terceiro e último encontro, realizaram a gravação do diálogo entre João e Mari, em PB, criado para esta pesquisa.

Todas as gravações dos dados dos informantes brasileiros foram realizadas com o uso do software Praat, instalado em um notebook Sony Vaio e um headset Microsoft Lifechat LX-3000, e as do informante americano, com o uso de um gravador Zoom H4. A todos os informantes foi solicitado que a leitura fosse realizada de modo que o diálogo soasse o mais natural possível. As respostas das interlocutoras, a esposa do informante americano e a pesquisadora (no caso dos informantes brasileiros), foram omitidas com o objetivo de auxiliar nessa tarefa, de modo que o locutor não as visualizasse e, por consequência, tivesse mais chances de fazer as perguntas de modo neutro, ou seja, em busca de uma informação desconhecida.

A seção a seguir descreve a atividade de produção oral realizada pelos informantes brasileiros, o teste de proficiência e seus resultados, que auxiliaram na escolha dos informantes cujas amostras foram efetivamente analisadas.

\section{O TESTE DE PROFICIÊNCIA}

O teste de proficiência teve como objetivo auxiliar na escolha dos informantes cujas amostras seriam analisadas. Um nível de proficiência muito baixo não era desejável já que outros fatores como a dificuldade para pronunciar sons da LA e a presença de pausas em demasia, comum para alguns aprendentes pouco proficientes, poderiam interferir na formação do desenho do contorno melódico e interferir na acuidade com que esses contornos pudessem ser descritos.

O teste foi desenvolvido a partir da gravação da Atividade de Produção Oral, no primeiro encontro com os nove informantes brasileiros. Essa atividade consistiu na descrição de uma sequência de nove lâminas no programa Power Point. Cada lâmina continha um determinado número de figuras, as quais deveriam ser descritas de modo isolado ou associado, a critério do informante. Foi explicado aos informantes que deveriam descrever apenas aquelas figuras sobre as quais possuíssem vocabulário de 
modo a não tornar a atividade uma tarefa que causasse desconforto. Antes de iniciar a descrição, um exemplo de como efetuar a tarefa foi dado. A sessão da gravação dessas amostras variou de 15 a 40 minutos.

As nove gravações foram analisadas e uma amostra com duração de 20 segundos foi recortada de cada áudio. Foram privilegiadas as amostras em que houvesse orações completas, pois elas "tendem a ser mais informativas e a gerar avaliações mais adequadas" (SILVEIRA, 2011, p. 77). Com o uso do programa de edição de áudio Sound Forge Audio Studio, as amostras foram normalizadas a $60 \mathrm{~dB}$ e todas as pausas longas foram removidas. Aleatoriamente, três amostras foram repetidas de modo a monitorar o desempenho das avaliadoras. A versão final do áudio do teste de proficiência (com as nove amostras, a repetição de três amostras e a inserção de pausas entre as amostras) teve oito minutos e quinze segundos de duração.

Este estudo contou com a participação de três avaliadoras brasileiras, altamente proficientes em inglês, com pós-graduação em inglês na área de Fonética e Fonologia. Para a execução da tarefa de avaliação do nível de proficiência oral, cada avaliadora recebeu, via email, o arquivo de áudio do Teste de Proficiência, um arquivo de áudio para treinamento, um arquivo com instruções e um arquivo com o formulário para registro da avaliação. Com base em Silveira (2011), foi explicado que os informantes variaram na quantidade de informação dada durante a descrição das lâminas e foi pedido que fizessem a avaliação, apoiando-se na "noção subjetiva de proficiência linguística do avaliador", de modo a "classificar os informantes de acordo com seu nível de proficiência" (SILVEIRA, 2011, p. 82). As avaliadoras ouviram o áudio contendo uma amostra de cada informante e avaliaram o nível de proficiência oral com o uso de uma escala tipo Likert de 0 (zero) - nível de proficiência oral muito baixo - a 10 (dez) nível de proficiência semelhante à do falante de inglês como língua materna.

Embora os valores atribuídos tenham variado entre as avaliadoras, o coeficiente Alpha de Cronbach (.942), utilizado para medir o grau de confiabilidade, indicou que o desempenho delas é confiável. As médias atribuídas variaram de 1,00 (nível de proficiência consideravelmente baixo) a 6,00 (nível intermediário de proficiência). $O$ teste de proficiência oral indicou que nenhum participante possuía um nível de proficiência semelhante à de um falante de inglês como língua materna. Apenas os participantes com as médias entre 3,00 e 6,00 ( $\mathrm{N}=5)$, ou seja, participantes 3, 4, 5, 2 e 9 (P3, P4, P5, P2 e P9), efetivamente tiveram as suas amostras de áudio analisadas 
posteriormente para responder às perguntas de pesquisa. P3, P4 e P5 foram, aqui, avaliados como possuindo um nível intermediário de proficiência oral, enquanto os participantes P2 e P9 foram avaliados como possuindo um nível básico de proficiência oral. Os demais participantes não tiveram suas amostras de áudio analisadas por terem um nível de proficiência oral identificado como muito baixo.

\section{RESULTADOS E DISCUSSÃO}

As 165 amostras de interrogativas totais dos participantes (15 amostras em PB e 15 em inglês de cada participante brasileiro; 15 amostras em inglês do informante americano) foram recortadas e os padrões entoacionais foram descritos através da notação do Sistema Métrico Autossegmental (L e H), com o auxílio do software de análise de fala - Praat. Quando o contorno melódico exibido pelo Praat não condizia com o escutado, um segundo pesquisador experiente na área de Prosódia e Entoação foi consultado.

Os padrões encontrados foram analisados comparativamente: (1) de acordo com a língua, considerando as versões do diálogo em português e em inglês, com vias a investigar se os padrões produzidos pelos falantes de PB diferiam ou não nas duas línguas; (2) de acordo com a língua materna, considerando as produções do falante inglês e dos falantes do PB, com vias a investigar se os padrões dos dois falantes se assemelhavam ou não; e (3) de acordo com o nível de proficiência, básico e intermediário, com vias a investigar se as semelhanças/diferenças encontradas eram as mesmas para os dois grupos, ou seja, se as interferências da L1 eram as mesmas para os dois níveis de proficiência.

\subsection{Padrões entoacionais das interrogativas totais no PB}

Os contornos melódicos das interrogativas totais encontradas no PB são, basicamente, (1) $\mathrm{LH}^{*} \mathrm{~L} \%$, (2) $\mathrm{L}+>\mathrm{H}^{*} \mathrm{~L} \%$ e (3) $\mathrm{H}+[\mathrm{LH}] * \mathrm{~L} \%$ (MORAES, 2008). A análise das 75 amostras do PB demonstrou, no entanto, uma produção de contornos melódicos mais variados, conforme Tabela 1 a seguir. 
Tabela 1: Padrões entoacionais produzidos pelos informantes brasileiros em $\mathrm{PB}$

\begin{tabular}{l|l|l|l|l|l}
\hline Contorno Melódico & P3 & P4 & P5 & P2 & P9 \\
\hline LH*L\% & 8 & 9 & 12 & 8 & 6 \\
LH*H\%T & 4 & 4 & 0 & 4 & 4 \\
LH*H\% & 2 & 2 & 3 & 3 & 4 \\
[LH]*L\% & 0 & 0 & 0 & 0 & 1 \\
HL*L\% & 1 & 0 & 0 & 0 & 0 \\
\hline
\end{tabular}

Apenas um dos contornos elencados por Moraes foi identificado, qual seja, o LH*L\%. Esse contorno indica que uma pergunta foi feita buscando uma informação desconhecida pelo locutor.

O contorno melódico descrito como LH*H\% é muito semelhante ao $\mathrm{LH}^{*} \mathrm{~L} \%$. Ele se distingue pelo seu final. Embora o Praat não faça o desenho do contorno do $\mathrm{H}^{*}$ para o L\%, é possível escutar esse movimento do pitch. Esse fenômeno é conhecido como "truncamento" e, geralmente, acontece quando há o apagamento de um ou mais sons ao final da palavra. A Figura 2 oferece um exemplo dessas duas notações.
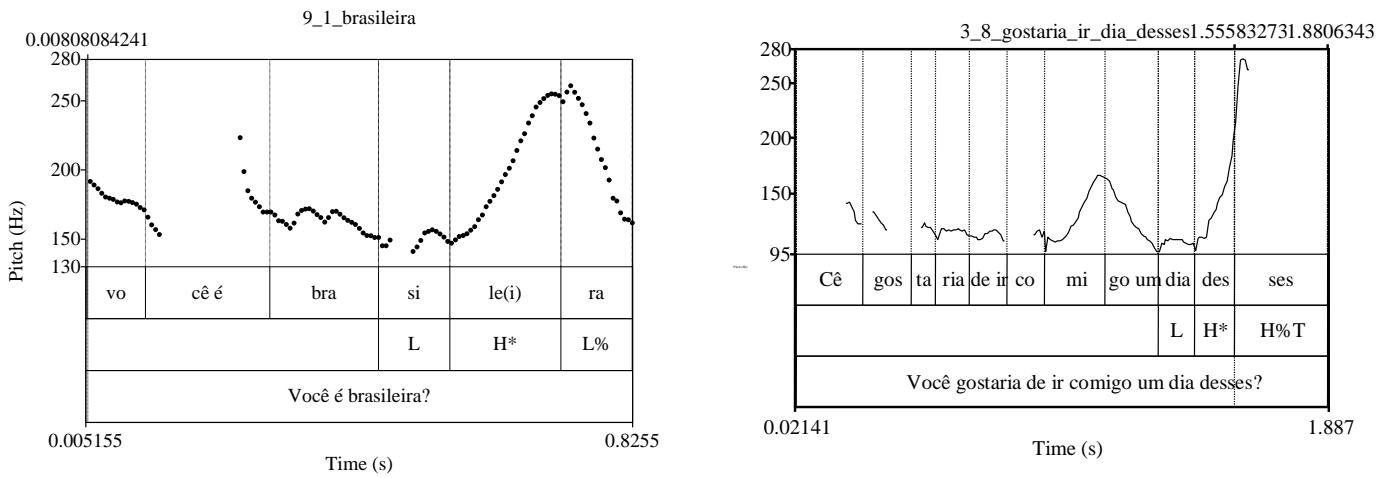

Figura 2: Notação LH*L\% - Interrogativa total neutra (à esquerda) e Notação LH*H\%T - Interrogativa total neutra com truncamento (à direita)

O contorno com a notação $\mathrm{LH}^{*} \mathrm{H} \%$ é finalizado com o tom de fronteira $\mathrm{H} \%$ em vez de L\%, como nos casos descritos na Figura 2. Essa notação se assemelha à de Moraes (2008), LH:*H\%, para o que ele chama de ênfase intensiva "intensive emphasis". A diferença entre as duas é o prolongamento da vogal tônica, simbolizado pelos dois pontos (:) após o H. Neste caso, não há apagamento e, consequentemente, não há truncamento. Portanto, o tom de fronteira L\% não é possível. Isso descaracteriza perguntas com esse contorno como sendo neutras. Como falante de PB como língua materna, a compreensão desta pesquisadora é de que interrogativas totais com esse contorno parecem sugerir uma suposta gentileza, doçura e cuidado por parte do locutor ao enunciar sua pergunta. 
Outro contorno encontrado foi o $[\mathrm{LH}] * \mathrm{~L} \%$, que se distingue do contorno melódico $\mathrm{LH}^{*} \mathrm{~L} \%$ no que tange à posição da tonicidade. Neste, a sílaba com o acento nuclear é o $\mathrm{H}^{*}$, antecedido por uma pré-nuclear $\mathrm{L}$; naquele, a sílaba com o acento nuclear é mais longa, iniciada com o L e finalizada com o H, seguido de uma sílaba com pitch mais baixo (L\%). De acordo com a interpretação desta pesquisadora, tal contorno melódico parece indicar uma suposta malícia e segunda intenção por parte do locutor ao enunciar sua pergunta. A Figura 3 ilustra esse contorno melódico e o descrito no parágrafo anterior $\left(\mathrm{LH}^{*} \mathrm{H} \%\right)$.
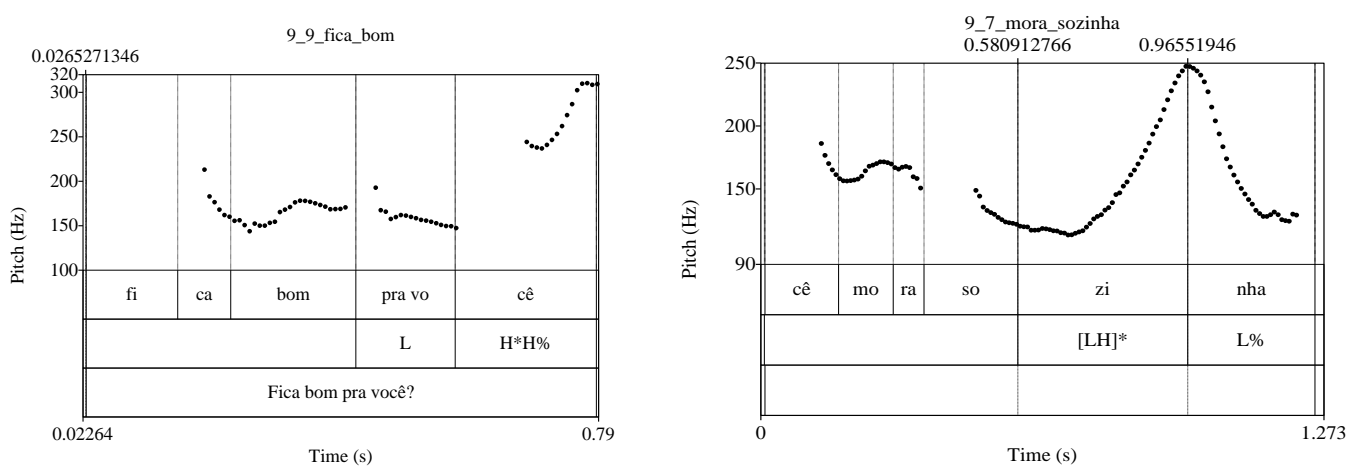

Figura 3: Notação $\mathrm{LH}^{*} \mathrm{H} \%$ - Interrogativa total com provável perda de neutralidade (doçura), à esquerda, e Notação [LH]*L\% - Interrogativa total com provável perda de neutralidade (segundas intenções), à direita.

Finalmente, o último padrão entoacional encontrado foi HL*L\%. Esse contorno melódico não corresponde ao da interrogativa total. De acordo com Moraes (2008), esse pode ser o padrão entoacional de declarativas, de perguntas do tipo $\mathrm{WH}$ ou, ainda, de pedidos. Como falante de PB como língua materna, essa pesquisadora interpretou essa melodia como indicativa de conclusão, e não de uma interrogativa em busca de informação desconhecida. A partir do contexto, o locutor parece ter chegado à conclusão de que a interlocutora estivesse de férias. A Figura 4 ilustra esse contorno.

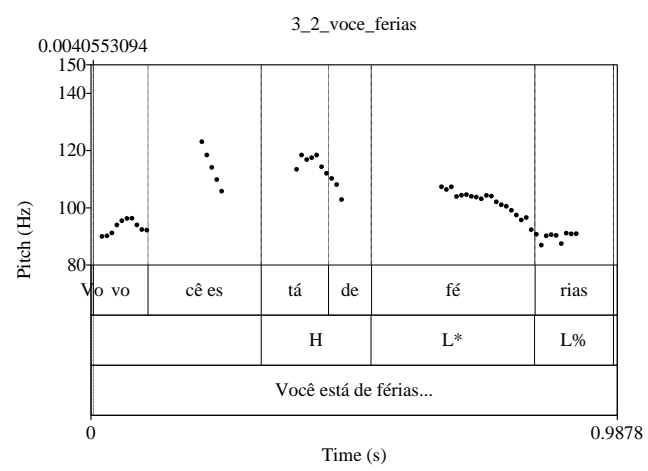

Figura 4: Notação HL*L\% - Interrogativa total com perda de neutralidade (declarativa de conclusão) 
A primeira hipótese de pesquisa previa que o padrão $\mathrm{LH}^{*} \mathrm{~L} \%$ seria $\mathrm{o}$ predominantemente encontrado nas produções das interrogativas nas amostras em PB, já que as perguntas foram realizadas sem a visualização da resposta. Essa primeira hipótese foi confirmada, uma vez que $57,33 \%$ das interrogativas $(\mathrm{N}=43)$ recebeu essa notação. No entanto, dada a natureza da atividade proposta para a coleta de dados, outros fatores como a interpretação, a emoção, a dramatização e as inferências do locutor, comuns na fala espontânea, podem ter interferido nessa produção, ocasionando, assim, o surgimento relevante de outras produções $(\mathrm{N}=32)$.

Dos quatro padrões entoacionais para interrogativas totais encontrados nos dados (o HL*L\% não foi considerado), apenas o LH*L\% foi utilizado para delimitar as análises das amostras em inglês. A notação $\mathrm{LH}^{*} \mathrm{H} \% \mathrm{~T}$, embora seja comparável à $\mathrm{LH}^{*} \mathrm{~L} \%$, também pode ser equiparada à $\mathrm{LH}^{*} \mathrm{H} \%$ devido ao apagamento e consequente truncamento. Esse fenômeno pode trazer informações importantes sobre a entoação do PB, mas investigá-lo está além do escopo do presente trabalho e, portanto, não foi explorado. A notação [LH]*L\% é uma outra notação que necessita de mais estudo e as amostras do PB sob esta notação também não tiveram as suas correspondentes em inglês discutidas nas seções a seguir.

\subsection{Padrões entoacionais das interrogativas totais no inglês americano}

Este estudo revisou quatro possíveis padrões para as interrogativas totais no inglês americano: (1) $\mathrm{H}^{*} \mathrm{HH} \%$, (2) $\mathrm{H}^{*} \mathrm{LL} \%$, (3) $\mathrm{H} * \mathrm{HL} \%$ e (4) $\mathrm{L} * \mathrm{HH} \%$, sendo essa última notação o foco do presente estudo, já que representa o contorno melódico das interrogativas totais neutras em inglês (HEDBERG; SOSA; FADDEN, 2004). A análise das amostras do informante americano (PAm) apontou a presença de dois padrões: (1) L*H\% e (2) LH*L\%. O padrão (1) foi reconhecido em 14 das 15 amostras e indica que elas foram interrogativas totais produzidas de forma neutra. Outro padrão encontrado foi o LH*L\%, também encontrado por Hedberg, Sosa, Görgülü e Mameni (2010) para uma das possibilidades de realização das interrogativas do tipo WH e também por Hedberg, Sosa e Fadden (2004) para a declarativa negativa. A Figura 5 ilustra os dois contornos encontrados nos dados deste trabalho para o PAm. 

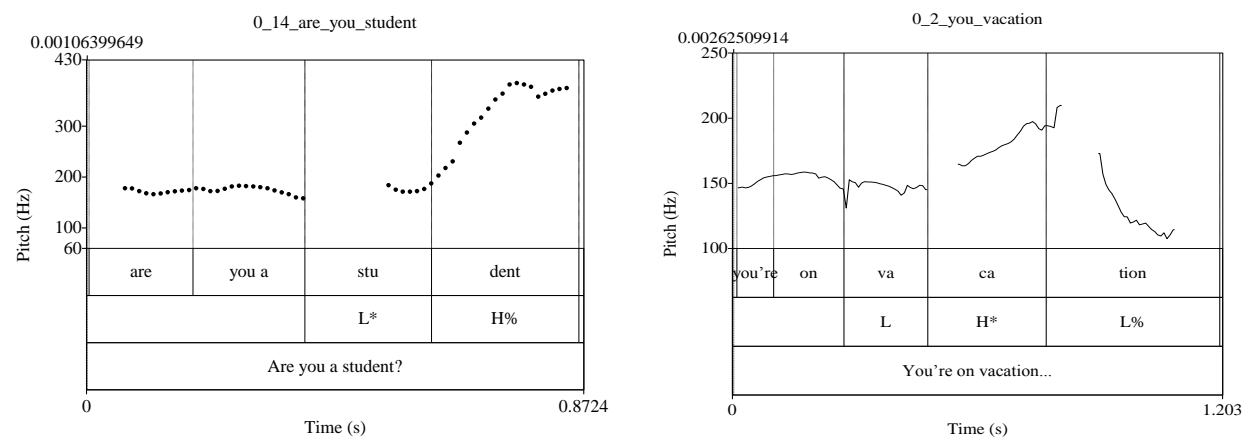

Figura 5: Notação L*H\% - Interrogativa total neutra do inglês americano, à esquerda, e Notação LH*L\% - Declarativa do inglês, à direita.

O fato de o PAm ter evitado a inversão sujeito-verbo na sua elocução já sinaliza a sua provável intenção de não postular uma interrogativa total neutra. Esse informante produziu praticamente o mesmo padrão que o P3 para a sua interrogativa correspondente, tanto no PB quanto no inglês.

A segunda hipótese levantada era de que o padrão L*H\% seria o mais frequente entre as amostras do informante americano e foi confirmada. Das 15 amostras, 14 foram produzidas de forma neutra e apenas uma foi produzida de forma declarativa, pois sofreu inferência de conteúdo por parte do informante.

A Tabela 2 apresenta os padrões entoacionais encontrados nas 90 amostras em inglês produzidas pelos informantes brasileiros e pelo informante americano.

Tabela 2: Padrões entoacionais das amostras em inglês

\begin{tabular}{l|l|l|l|l|l|l}
\hline Contorno Melódico & PAm & P3 & P4 & P5 & P2 & P9 \\
\hline L*H\% & 14 & 13 & 11 & 11 & 6 & 6 \\
LH*L\% & 1 & 2 & 1 & 3 & 4 & 6 \\
L*!H\% & 0 & 0 & 2 & 0 & 2 & 1 \\
H*H\% & 0 & 0 & 1 & 1 & 0 & 0 \\
LH*H\%T & 0 & 0 & 0 & 0 & 1 & 0 \\
L*L\% & 0 & 0 & 0 & 0 & 1 & 1 \\
H*L\% & 0 & 0 & 0 & 0 & 1 & 1 \\
\hline
\end{tabular}

Os dados do contorno melódico exibidos na Tabela 2 indicam que houve uma variação na produção do contorno melódico especialmente para os P4 (4), P2 (6), e P9 (5) no inglês, cujo nível de proficiência foi avaliado como baixo. Além dos padrões encontrados na produção do PAm ( $\mathrm{L} * \mathrm{H} \%$ e LH*L\%), outros cinco contornos melódicos foram identificados: (1) L*!H\%, (2) $\mathrm{H}^{*} \mathrm{H} \%$, (3) LH*H\%T, (4) L*L\% e (5) H*L\%.

O contorno melódico $\mathrm{L}^{*} ! \mathrm{H} \%$ simboliza uma tentativa de alcançar o padrão melódico $\mathrm{L}^{*} \mathrm{H} \%$. O locutor tenta, mas não consegue subir o suficiente para que a sua produção receba a notação H\%. O locutor inicia o acento nuclear em L e começa a subir 
até chegar à sílaba pós-tônica, mas não consegue subir mais e mantém aquela altura até o tom de fronteira ! $\mathrm{H} \%$ (sobe apenas $34 \mathrm{~Hz}$ enquanto o PAm sobe $172 \mathrm{~Hz}$ ).

O contorno melódico $\mathrm{H}^{*} \mathrm{H} \%$ (ou $\mathrm{LH}^{*} \mathrm{H} \%$ ) é semelhante ao $\mathrm{L}^{*} \mathrm{H} \%$. Ele se distingue pelo seu início, que já começa alto. Em inglês, essa notação pode ser usada para indicar surpresa por parte do locutor (HEDBERG; SOSA; FADDEN, 2004). A Figura 6 traz uma ilustração dessa notação e da notação /L*!H\%.
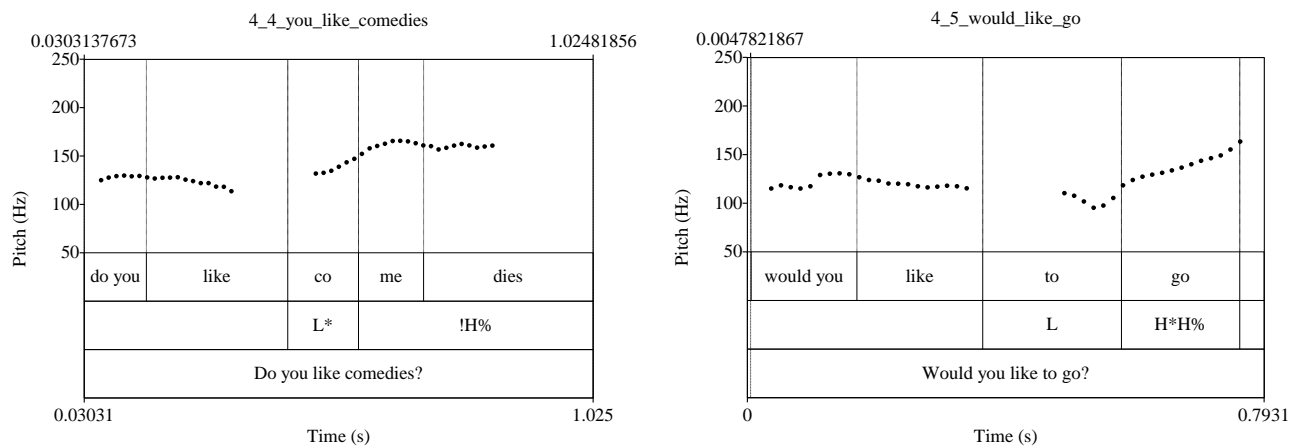

Figura 6: Notação L*!H\% - Interrogativa total neutra (tentativa), à esquerda, e Notação $\mathrm{H}^{*} \mathrm{H} \%$ - Interrogativa total em inglês (surpresa), à direita.

O contorno melódico LH*H\% Té muito semelhante ao LH*L\%. Ele se distingue pelo tom de fronteira. Embora o Praat não faça o desenho do contorno a partir do $\mathrm{H}^{*}$ até o L\%, é possível escutar esse movimento do pitch, indicando a presença de truncamento. A Figura 7 traz uma ilustração dessa notação.

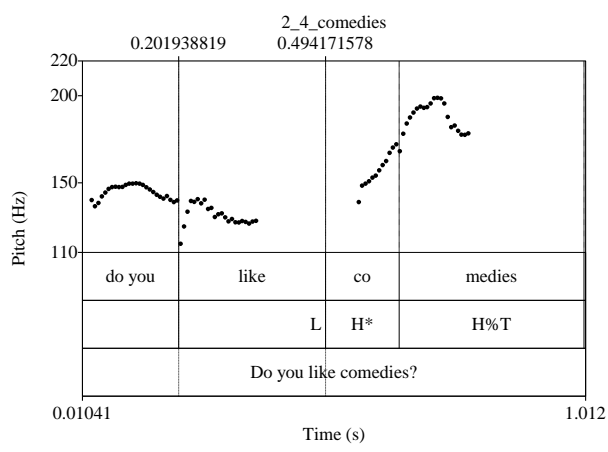

Figura 7: Notação LH*H\%T - Interrogativa total em inglês com influência da declarativa e truncamento.

Os contornos melódicos $\mathrm{L}^{*} \mathrm{~L} \%$ e $\mathrm{H}^{*} \mathrm{~L} \%$ se distinguem do $\mathrm{L} * \mathrm{H} \%$ por não haver movimento ascendente do pitch, terminando no tom de fronteira $\mathrm{L} \%$ (L*L\%) ou por possuir um movimento descendente culminando no tom de fronteira $\mathrm{L} \%\left(\mathrm{H}^{*} \mathrm{~L} \%\right)$, incomum nas interrogativas totais neutras do inglês. Esses movimentos desconfiguram a interrogativa total como sendo neutra. A Figura 8 ilustra esses contornos. 

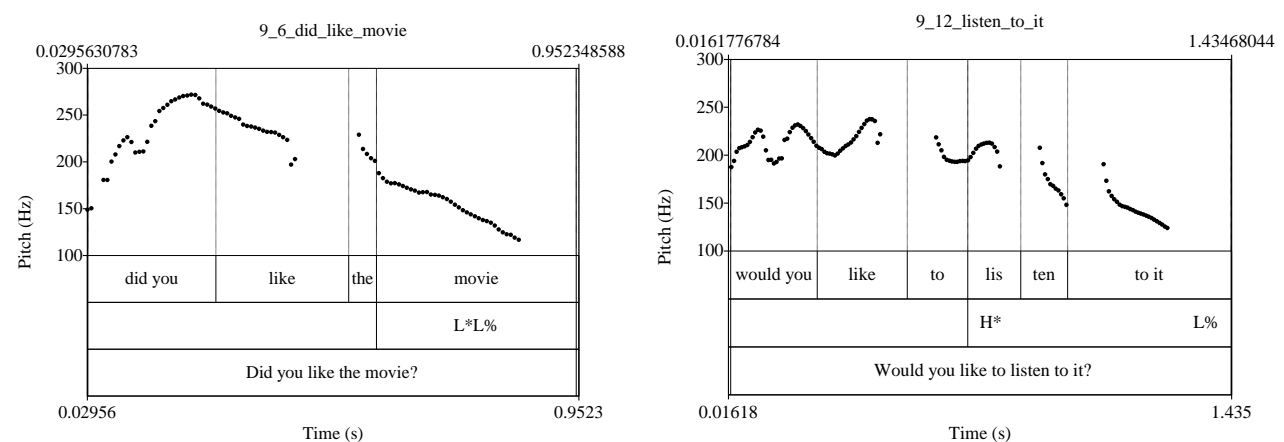

Figura 8: Notação L*L\% (à esquerda) e $H^{*} L \%$ (à direita) - Interrogativas totais em inglês com comprometimento do valor neutro.

A terceira hipótese previa que os padrões entoacionais das interrogativas totais encontradas nas produções dos informantes brasileiros em inglês seriam o representado pela notação LH*L\% em sua maioria e não foi confirmada. Das 75 amostras, apenas $21,33 \%(\mathrm{~N}=16)$ receberam essa notação. $\mathrm{O}$ padrão entoacional $\mathrm{L} * \mathrm{H} \%$ foi encontrado na maior parte das amostras $(62,66 \% ; \mathrm{N}=47)$ e $16 \%(\mathrm{~N}=12)$ foram produzidas de outras maneiras (L*!H\%, H*H\%, LH*H\%T, L*L\% e H*L\%).

Ao revisitar os dados da Tabela 2, algumas proposições podem ser feitas se a variável nível de proficiência for considerada. A Tabela 3 traz os dados sobre os padrões entoacionais em inglês produzidos pelos informantes brasileiros de acordo com o nível de proficiência.

Tabela 3: Comparação dos padrões encontrados em inglês de acordo com o nível de proficiência

\begin{tabular}{l|c|c}
\hline Nível de Proficiência & Nível Básico $(\mathrm{N}=30)$ & Nível Intermediário $(\mathrm{N}=45)$ \\
\hline L*H\% & $40 \%(\mathrm{~N}=12)$ & $77,77 \%(\mathrm{~N}=35)$ \\
LH*L\% & $33,33 \%(\mathrm{~N}=10)$ & $13,33 \%(\mathrm{~N}=6)$ \\
Outros & $26,66 \%(\mathrm{~N}=8)$ & $8,88 \%(\mathrm{~N}=4)$ \\
\hline Total de padrões diferentes do & & \\
L*H\% & $59,99 \%(\mathrm{~N}=20)$ & $22,22 \%(\mathrm{~N}=10)$ \\
\hline
\end{tabular}

Das 30 amostras produzidas em inglês pelos participantes no nível básico de proficiência, $40 \%(\mathrm{~N}=12)$ foram produzidas com o padrão entoacional $\mathrm{L} * \mathrm{H} \%$ enquanto 59,99\% ( $\mathrm{N}=20)$ foram produzidas com padrões diferentes. As produções dos informantes no nível intermediário de proficiência obtiveram 77,77\% ( $\mathrm{N}=35)$ de correspondência com o padrão $\mathrm{L}^{*} \mathrm{H} \%$ e apenas $22,22 \%(\mathrm{~N}=10)$ de não correspondência. Esses dados confirmam a quarta hipótese que previa esse comportamento. 


\subsection{Produção das interrogativas totais neutras do PB correspondentes em inglês}

A Tabela 4 compara as interrogativas produzidas no PB como neutras ( $\mathrm{LH}^{*} \mathrm{~L} \%$ ) com as suas correspondentes em inglês, para cada participante. A coluna " $\mathrm{N}$ " inclui o número de amostras, a coluna "Igual" o percentual de amostras produzidas em inglês com o mesmo padrão entoacional que em PB (LH*L\%), a coluna "Diferente", o percentual de amostras produzidas de forma diferente do padrão entoacional do inglês ( $\left.\mathrm{L}^{*} \mathrm{H} \%\right)$ e a coluna "Outros Padrões", apresenta o número de vezes em que essa diferença não traduz essa transferência direta do PB para o inglês.

Tabela 4: Comparação dos contornos em PB e em inglês por participante (percentual de produção do mesmo contorno nas duas línguas para perguntas equivalentes)

\begin{tabular}{c|l|l|l|l|l}
\hline Nível de Proficiência & Participantes & $\mathrm{N}$ & $\begin{array}{r}\text { Igual a } \\
\text { LH*L\% }\end{array}$ & $\begin{array}{c}\text { Diferente de } \\
\text { L*H\% }\end{array}$ & $\begin{array}{c}\text { Outros } \\
\text { Padrões }\end{array}$ \\
\hline \multirow{3}{*}{ Intermediário } & P3 & 8 & $12,5(1)$ & $12,5(1)$ & $0(0 \%)$ \\
& P4 & 8 & $12,5(1)$ & $37,5(3)$ & $2(66,6 \%)$ \\
& P5 & 11 & $16,7(2)$ & $27,3(3)$ & $1(33,3 \%)$ \\
\hline \multirow{2}{*}{ Básico } & P2 & 7 & $42,9(3)$ & $71,4(5)$ & $2(40 \%)$ \\
& P9 & 5 & $40,0(2)$ & $60,0(3)$ & $1(33,3 \%)$ \\
\hline
\end{tabular}

Os participantes P3, P4 e P5, cujo nível de proficiência foi avaliado como intermediário, produziram as interrogativas em inglês no máximo $17 \%$ como no PB. Isso indica que, neste estágio de desenvolvimento da LA, esses informantes se basearam nos padrões entoacionais das interrogativas totais neutras da sua língua materna com pouca frequência. Portanto, a influência direta da L1 sobre a LA foi baixa.

No caso dos participantes P2 e P9, cujo nível de proficiência foi avaliado como básico, a incidência de produção dos padrões entoacionais das interrogativas neutras do PB em inglês foi maior $(42,9 \%$ e $40 \%$, respectivamente). Isso sugere que a transferência direta desses padrões da L1 para a LA aconteceu com mais frequência, o que corrobora resultados sobre pesquisa no nível segmental que indicam que, no início do processo de aprendizagem, os aprendentes se baseiam na sua L1 para as produções na LA. É importante observar, no entanto, que essa influência direta não aconteceu com uma frequência alta (menos de 50\%), o que pode indicar que outros fatores podem ter influenciado a produção dos padrões entoacionais na LA.

O participante P3 produziu apenas uma dentre as oito interrogativas analisadas com um padrão diferente do $\mathrm{L} * \mathrm{H} \%$ (neutro em inglês) e manteve sua produção consistente. Em outras palavras, em apenas uma das oito produções, ele transferiu o 
padrão $\mathrm{LH}^{*} \mathrm{~L} \%$ do $\mathrm{PB}$ para a sua produção em inglês, diretamente e não parece ter havido nenhum outro tipo de influência.

Os participantes P4, P5, P2 e P9, no entanto, apresentaram uma produção diferente, ou seja, o LH*L\% não é a notação que representa todas as diferenças de produção do padrão entoacional em inglês. Os dados demonstram que em mais de 30\% dos casos, não houve transferência direta do padrão entoacional LH*L\% para o inglês para os participantes P4, P5, P2 e P9. Esses padrões que surgiram foram L*!H\%, $\mathrm{LH}^{*} \mathrm{H} \% \mathrm{~T}, \mathrm{H}^{*} \mathrm{H} \%, \mathrm{~L}^{*} \mathrm{~L} \%$ e $\mathrm{H}^{*} \mathrm{~L} \%$, os três últimos padrões identificados como existentes em inglês (HEDBERG; SOSA; FADDEN, 2004), mas não representantes da interrogativa neutra; os dois primeiros, até onde a revisão da literatura deste estudo explorou, são padrões novos. A priori, esses padrões podem ser interpretados como padrões representativos da "língua do aprendente" ou da interlíngua de cada participante. No que concerne à entoação, os padrões entoacionais para as interrogativas totais ainda parecem estar em desenvolvimento, incluindo produções com influência direta da L1 ou de outros fatores. Esses fatores podem estar relacionados à possível percepção do locutor do padrão $\mathrm{L}^{*} \mathrm{H} \%$, ao seu desejo de alcançá-lo, e à sua inabilidade de fazê-lo. Isso fica claro principalmente para a notação $\mathrm{L} * \mathrm{H} \%$ (não é um padrão entoacional que se pretenda alcançar).

A quinta hipótese sugeriu que esses resultados poderiam ser explicados à luz da transferência linguística e foi parcialmente confirmada. Os participantes cujo nível de proficiência era o básico produziram a maior parte dos contornos melódicos de forma dissonante do padrão da interrogativa total neutra em inglês. Isso se dá por terem de lidar com outros fatores durante o processo de uso da língua, tais como dificuldades de pronúncia e vocabulário desconhecido, deixando os elementos prosódicos como a entoação para segundo plano. Desta forma, utilizaram-se mais de outros padrões, mesmo que eles não fossem uma transferência direta da sua L1.

O surgimento de outros padrões que não $\mathrm{LH}^{*} \mathrm{~L} \%$ nas produções em inglês aconteceu para quase todos os participantes, exceto para o participante P3, e sugere uma possível entoação em desenvolvimento (entoação própria da língua do aprendente).

$\mathrm{O}$ participante $\mathrm{P} 3$, que provavelmente já tem o padrão entoacional da interrogativa total neutra do inglês desenvolvido, distingue-se dos demais participantes no que se refere ao tempo de aprendizagem da língua adicional que foi o de onze anos, iniciado no Ensino Fundamental (Séries iniciais, aos seis ou sete anos de idade) e 
concluído no curso da Escola Naval (equivalente a um curso de graduação). Os participantes P2, P4 e P5 tiveram um tempo médio de cinco anos de experiência com a aprendizagem e parecem ter o padrão entoacional da interrogativa total neutra do inglês ainda em desenvolvimento.

Além do tempo de aprendizagem, outro fator que parece ter exercido alguma influência foi a idade ao iniciar a aprendizagem da LA. O participante P9, cujo padrão entoacional da interrogativa total neutra em inglês parece ainda estar em desenvolvimento, embora tenha reportado o estudo da LA por aproximadamente dez anos, iniciou-o no Ensino Médio, aos quinze anos de idade, interrompendo-o após o curso de ensino superior (sete anos depois) e retomando-o em momentos subsequentes.

Os resultados aqui discutidos colaboram para a proposta de existência de uma língua do aprendente que, concernente à entonação, além das características dos padrões entoacionais da L1 e da LA, inclui padrões alternativos próprios e reveladores dessa língua em desenvolvimento.

\section{CONSIDERAÇÕES FINAIS}

Este estudo investigou os padrões entoacionais das interrogativas totais neutras em português e em inglês produzidos por falantes brasileiros de inglês como língua adicional com nível básico e nível intermediário de proficiência oral.

A primeira hipótese de pesquisa previa que o padrão $\mathrm{LH}^{*} \mathrm{~L} \%$ seria $\mathrm{o}$ predominantemente encontrado nas produções das interrogativas nas amostras em PB e foi confirmada. No entanto, dada a natureza da atividade proposta pela coleta de dados, outros fatores como a interpretação, emoção, dramatização e inferências do locutor podem ter interferido nessa produção, ocasionando o surgimento relevante de outras produções. A segunda hipótese previa que o padrão $\mathrm{L} * \mathrm{H} \%$ seria o predominantemente encontrado nas amostras do informante americano e foi confirmada. A terceira hipótese previa que os padrões entoacionais das interrogativas totais encontradas nas produções dos informantes brasileiros em inglês seriam o representado pela notação $\mathrm{LH}^{*} \mathrm{~L} \% \mathrm{em}$ sua maioria e não foi confirmada. A quarta hipótese previa uma diferença na produção dos padrões entoacionais do grupo de nível básico de proficiência se comparado ao 
intermediário e foi confirmada. A quinta hipótese sugeriu que esses resultados poderiam ser explicados à luz da transferência linguística e foi parcialmente confirmada.

Os participantes cujo nível de proficiência era o básico produziram a maior parte dos contornos melódicos de forma dissonante do padrão da interrogativa total neutra em inglês. Isso pode ser explicado pelo fato de esses participantes terem de processar informações relacionadas a outros fatores como a pronúncia e vocabulário desconhecido em primeiro plano, deixando, para segundo plano, elementos prosódicos como a entoação. Desta forma, utilizaram-se mais de outros padrões, mesmo que eles não fossem uma transferência direta da sua L1.

Outros fatores que não a L1 também pareceram ser importantes, tais como (1) o tempo de aprendizagem da LA e (2) a idade de início da aprendizagem da LA. Embora de forma singela, os resultados aqui discutidos colaboram para a ideia da existência de uma língua do aprendente que, no que tange à entoação, além dos contornos dos padrões entoacionais da L1 e da LA, inclui padrões entoacionais característicos dessa língua adicional em desenvolvimento.

Esse estudo apresentou duas limitações importantes. A primeira se refere à dificuldade de encontrar padrões de interrogativas neutras nas leituras dos diálogos. As possibilidades de produções caíram de 15 para até cinco em alguns casos. Pesquisas futuras poderiam replicar o estudo através da leitura das perguntas fora de um contexto ou através de jogos como, por exemplo, Cara a Cara. A segunda também se refere à coleta de dados, mais especificamente, à gravação dos diálogos. Os informantes brasileiros gravaram os diálogos com a participação desta pesquisadora, que é proficiente em inglês. Na condição de aprendente, acostumado a seguir modelos, os informantes, principalmente os de nível intermediário de proficiência, podem ter sido influenciados pelos padrões entoacionais por ela produzidos, o que pode ter alterado o resultado deste estudo (as diferenças foram encontradas principalmente nas interrogativas no primeiro terço do diálogo).

Além do padrão entoacional $\mathrm{LH}^{*} \mathrm{~L} \%$, outros padrões entoacionais surgiram na produção dos informantes brasileiros. Pesquisas futuras poderiam investigar como esses padrões são compreendidos por ouvintes falantes de inglês cuja L1 não seja o PB e que interferências reais poderiam trazer à interação mútua/comunicação. Essa compreensão influenciará as decisões acerca do que incluir no que tange ao ensino de pronúncia e entoação nas aulas de inglês como língua adicional no Brasil. 


\section{AGRADECIMENTOS}

Agradeço ao Professor Doutor Juan Manuel Sosa pelas valiosas contribuições nas notações dos padrões entoacionais, à Professora Doutora Rosane Silveira pelas orientações para a elaboração da atividade de produção oral e para o Teste de Proficiência Oral, às avaliadoras do Teste de Produção Oral, à pesquisadora Larissa Buss pela colaboração na coleta de dados, aos informantes por participarem desta pesquisa, à Escola de Aprendizes-Marinheiros de Santa Catarina por ter permitido o acesso para a coleta de dados, e aos avaliadores anônimos por suas contribuições.

\section{REFERÊNCIAS}

BERNS, M. World Englishes, English as a lingua franca, and intelligibility. World Englishes, 27(3), 327-334, 2008.

CRUZ, N. C. Vowel insertion in the speech of Brazilian learners of English: a source of unintelligibility? Ilha do Desterro - A Journal of English Language, Literatures in English and Cultural Studies, (55), 133-152, 2010. Disponível em: http://www.journal.ufsc.br/index.php/desterro/article/viewArticle/16307. Data de acesso: 03 de abril de 2013.

CRUZ, N. C. Familiaridade do ouvinte e inteligibilidade da pronúncia de aprendizes brasileiros de inglês. Revista Horizontes de Lingüística Aplicada, 7(1), 88-103, 2008.

An exploratory study of pronunciation intelligibility in the Brazilian Learner's English. The ESPecialist, 24(2), 155-175, 2003.

ECKMAN, F. From phonemic differences to constraint rankings: Research on Second Language Phonology. Studies in Second Language Acquisition, v. 26, p. 513-549, 2004.

FIVE GRACES GROUP, The. Language is a complex adaptive system: Positional paper. Language Learning, v. 59, s. 1, p. 1-26, 2009.

HEDBERG, N.; SOSA, J. M.; FADDEN, L. "Meanings and Configurations of Questions in English". Proceedings of Speech Prosody 2004, Nara, Japan, 2004. Disponível em <http://www.sfu.ca/ hedberg/Hed_Sos_Fad_Fin_2004.pdf >. Data de acesso: 07 de abril de 2013.

HEDBERG, N., SOSA, J. M., GÖRGÜlÜ, E., MAMENI, M. The Prosody and Meaning of Wh-Questions in American English. In: Speech Prosody 2010, Chicago, Illinois. May 11-14, 2010. Disponível em http://www.sfu.ca/ hedberg/Hed_Sos_Gor_Mam_2010.pdf. Data de acesso: 15 de abril de 2013.

JENKINS, J. Community, Currency and the Lingua Franca Core. TESOL Spain Newsletter, v. 26, Spring 2003.

LADD, D. R. Phonological representation of pitch in the autosegmental-metrical theory. In: _ Intonational phonology. Cambridge: Press Syndicate of the University of Cambridge, p. 79-112, 1996.

.Fundamental concepts of the autosegmental-metrical theory. In:

Intonational phonology. Cambridge: Press Syndicate of the University of Cambridge, p. 43-84, 2008. 
MORAES, J. A. de. The pitch accents in Brazilian Portuguese : analysis by synthesis, Speech Prosody, Campinas, may - 2008. Disponível em <http://www.iscaspeech.org/archive/sp2008/papers/sp08_389.pdf>. Data de acesso: 12 de abril de 2013.

SCHADECH, T. S; SILVEIRA, R. How do the non-target pronunciations of the consonants $/ \Theta /$ and $/ \delta /$ by Brazilian learners of English affect comprehensibility? Cadernos do IL, v. 1, p. 4-23, 2013.

SEARA, I. C. Fonética e fonologia do Português Brasileiro. 1 e.d. Florianópolis: LLV/CCE/UFSC, 2008. v. 1, 115p.

SILVEIRA, R. Avaliando a proficiência oral em língua inglesa: o papel dos avaliadores e dos informantes. In: Mota, Mailce Borges; Bergsleithner, Joara Martin; Weissheimer, Janaína. (Org.). Produção Oral em LE: Múltiplas Perspectivas. Campinas: Pontes, 2011, v. 19, p. 73-96, 2011. 